\title{
DAMAGE MODE IDENTIFICATION IN TRANSVERSE CRACK TENSION SPECIMENS USING ACOUSTIC EMISSION AND CORRELATION WITH FINITE ELEMENT PROGRESSIVE DAMAGE MODEL
}

\author{
Fatih E. Oz ${ }^{1}$, Sina Ahmadvashaghbash ${ }^{2}$ and Nuri Ersoy ${ }^{3,4}$

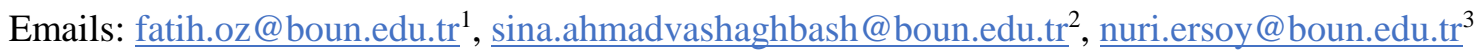

\begin{abstract}
In this study damage progression in unidirectional composite specimens is investigated. Transverse Crack Tension specimens are used to stimulate damage in a predetermined progressive sequence. Acoustic Emission (AE) registration technique and its location detection capability is used to identify and locate the damage modes during the tension tests. The k-means++ algorithm is applied to cluster similar AE events and obtain reliable correlations between the damage modes and AE characteristics. Damage modes at the end of interrupted tests are identified under an optical microscope and correlated with locations of AE clusters. It is seen that matrix cracks have high amplitude and duration, whereas delaminations have low amplitude and mid-duration, and fibre breaks have high average frequency characteristics. A finite element analysis was performed to predict the progressive failure behaviour including intralaminar failure and delaminations. The correlations between the AE clusters and damage modes are validated with the finite element model.
\end{abstract}

Keywords: Polymer-matrix composites (PMC), Transverse cracking, Acoustic emission, Finite Element Analysis (FEA)

\section{Introduction}

Damage detection and identification in composite materials is a very difficult task, given the multitude and complexity of the damage modes. Damage initiation occurs at a microscopic level in terms of matrix cracking and propagates to large damage modes such as delamination and fibre breaks at the end. Besides, 
there is not an obvious yield point or slope change in tensile stress-strain curves of composite materials as seen in metallic materials. In fact, the tensile stress-strain curves of Carbon Fibre Reinforced Polymer (CFRP) laminates show stiffening behaviour because of the non-Hooken behaviour of carbon fibres due to crystallite misorientations [1-4]. This is more prominent in unidirectional (UD) [0] $]_{\mathrm{n}}$ type CFRP laminates which have an upwardly concave stress-strain curve. Thus, it is not possible to identify damage modes and determine their stress levels from the stress-strain curves of UD CFRP composites only.

A micrograph of a $[0]_{5}$ specimen, captured around $92 \%$ of the ultimate strength is shown in Figure 1 . The individual fibre breaks are the only damage mode up to this load level whereas other damage modes, such as, matrix cracking, fibre/matrix splitting or delaminations cannot be detected by microscopic observations. Therefore, the application of only microscopic observations during the tension tests of $[0]_{n}$ laminates are considered inadequate in detecting the damage levels and even identifying all possible damage modes. Additional techniques are required for these purposes.

Figure 1 . Fibre breaks at $92 \%$ of the ultimate strength of $[0]_{5}$ specimen

Acoustic Emission (AE) technique is considered as an important method for damage mode identification in composite materials. There exist numerous studies in the literature that have applied this technique during mechanical tests of various types of composite materials under different loading modes. Most of the studies are focused on the damage progression during quasi-static tension tests [4-29]. Generally, multi-angular laminates are involved since they include all damage modes which is important to increase the efficiency of $\mathrm{AE}$ registration technique in terms of identification of different damage modes. However, there are limited number of studies that investigate the damage progression in $\mathrm{UD},[0]_{\mathrm{n}}$, laminates under tension in the fibre direction $[6,12,13,16,19,25,27]$.

De Groot et. al [6] tested uncured prepreg and cured $[0]_{8}$ laminates and observed the registration of high peak frequency AE events during UD tension tests which were believed to be due to fibre breaks. RamirezJimenez and Loutas et. al $[12,13]$ proposed a correlation between the high frequency AE events and the 
fibre breaks due to the agreement between the early registered high peak frequency AE events and the expected fibre breaks at low strains. Gutkin et. al [16] considered the same trend for AE classification of prementioned damage modes [16]. However, high peak frequency events were not observed during the tension tests of $[0]_{8}$ laminates and it was assumed that the $\mathrm{AE}$ was not able to register the high frequency signals due to a large energy release during the final failure of the specimen when fibre failure occurs [16]. Mohammadi et. al [27] investigated the damage in open-hole (OH) glass-fibre reinforced polymer (GFRP) composite under tension test with $\mathrm{AE}$ technique and compared the results with finite element (FE) predictions. In order to determine the AE characteristics of different damage modes, tension tests were applied to single constituents first, and then the AE events registered during the tension tests of OH UD GFRP were classified according to the results of single constituents' tests [27]. A correlation was built between the AE correspondence of damage modes and the FE progressive damage model predictions. All these studies conclude with the correlation of low peak frequency events with matrix cracks and high peak frequency events with fibre breaks.

In order to determine the damage modes and their AE characteristics in UD composites during tension tests, non-uniform, specially designed specimens were tested with simultaneous optical observations. Prieß et al. [19] applied transverse crack tension (TCT) test with AE technique to detect delamination onset in UD CFRP composites. The TCT specimen is a UD specimen containing slits due to the cut fibres through the width of the specimen in the centre where it is filled with resin at the end of the manufacturing. Damage initiation occurs with matrix cracking at the fibre-end/matrix interface of the resin pocket and causes delamination from the corners of this pocket at a certain load level [19,30,31]. Evaluation of AE results with a pattern recognition technique and its correlation with the through-thickness measurements of 3D Digital Image Correlation (DIC) technique enabled to detect the stress levels for delamination onset [19]. However, this study did not attempt to correlate all damage modes with AE characteristics, and relied on the findings of a previous study [32] to identify damage modes by clustering. Furthermore, optical observations at the edge of the specimen are inconclusive to correlate the damage modes to AE clusters. 
The TCT tests were applied by Fotouhi et al [25] to UD hybrid laminates consisting of glass/carbon/glass layers, containing a cut opened to mid carbon layer, with AE registration. Damage in carbon layers was seen on the surface glass layer easily due to the translucent nature of the latter. This enabled to correlate delamination and ply fragmentation with AE events respectively [25].

In this study, the TCT tests are applied to CFRP UD, $[0]_{5}$ specimens and are investigated with AE registration technique. Slits are opened to the centre of the mid-ply $\left(3^{\text {rd }} \mathrm{ply}\right)$ of the laminates by cutting the fibres through their width, which enables to observe the damage progression in a predetermined order: matrix cracking - fibre/matrix debonding - delamination - fibre breaks. The TCT tests are stopped at stress levels before the ultimate strength and free edges of the specimens are investigated under an optical microscope to identify the induced damage modes. In order to have reliable correlations between the damage modes and AE characteristics, the k-means++ clustering algorithm is used to group similar AE events. It is seen that the $\mathrm{AE}$ localization technique provides a good correlation between damage mode progression and accumulation of $\mathrm{AE}$ results. Test results enable to see that; matrix cracks and fibre/matrix debonding in resin pockets have high amplitude and duration characteristics, whereas delaminations have low amplitude and mid-duration characteristics and fibre breaks have high average frequency characteristics. Moreover, both intralaminar failure and delamination are investigated with a Finite Element Analysis (FEA) to verify AE results. It is found that the proposed progressive failure model exhibits a very good agreement with the test results in terms of damage progression and the correlations between the $\mathrm{AE}$ clusters and damage modes are validated with the FEA.

\section{Experimental work}

\subsection{Material and manufacturing}

In this study, specimens are made from Hexcel's unidirectional (UD) AS4/8552 prepregs [33]. HexPly® 8552 is an amine cured, toughened and high-performance epoxy resin system reinforced with UD AS4 carbon fibres for use in primary aerospace structures [33]. Its fibre volume fraction and nominal thickness 
are $57.4 \%$ and $0.184 \mathrm{~mm}$ respectively. Mechanical properties of a cured UD ply are shown in Table 1. Since limited data is available in the technical data sheet [33], predictions obtained by FE micromechanical analysis are given in Table 1.

Table 1. Mechanical properties of AS4/8552

The TCT specimens are produced by incorporating slits into the $[0]_{5}$ laminates by cutting fibres of mid-ply $\left(3^{\text {rd }}\right)$ of the laminates before lay-up. The height of the slit is $0.5 \mathrm{~mm}$ (equal to the thickness of the knife, used to open the slit) and the thickness of the slit is equal to the thickness of a single ply. At the end of the curing, slit regions are filled with resin and resin pockets are obtained in test specimens. The TCT specimen is designed to stimulate damage and make damage progression in a predetermined order of matrix cracking, fibre/matrix debonding, delamination and fibre breaks.

Recommendations in ASTM D3039 Test Standard [34] are taken into consideration for the specimen geometry. A UD $[0]_{5}$ plate, having $150 \mathrm{~mm}$ width and $250 \mathrm{~mm}$ length, is manufactured in an autoclave according to the Manufacturers Recommended Cure Cycle (MRCC) [33]. Quasi-isotropic glass fibre reinforced epoxy end tabs with $1.5 \mathrm{~mm}$ thickness and $56 \mathrm{~mm}$ length are attached to the plate. Their gage section ends are tapered to $20^{\circ}-30^{\circ}$ to minimize stress concentrations at the tab-grip intersections and to prevent failure from grip sections during tension tests. Then $25 \mathrm{~mm}$ width specimens are cut from these plates with a water-cooled diamond saw. Thus, $[0]_{5}$ specimens consisting of resin pockets through their width in mid-plies are obtained. Finally, specimen edges are ground and polished carefully for observations with an optical microscope to capture damage progression during testing. The sketches of the TCT specimens with slits are shown in Figure 2.

Figure 2. Schematic views of slit in TCT specimens 


\subsection{Tension test procedure}

Tension tests are performed according to ASTM D3039 Test Standard [34], using a computer controlled servo-hydraulic Instron 8801 test machine with $100 \mathrm{kN}$ load cell. Bluehill 3.0 software is used to control test parameters and data acquisition. Displacements and strain measurements in axial and transverse directions are done by using video extensometer. Five specimens are tested with AE registration technique in total. First two tests end up with final failure. Important stress levels are determined from these tests by using the cumulative number of registered AE events plotted together with the stress-strain curve. Then interrupted tests are applied to three specimens until the determined interruption stress levels, lower than the ultimate strength. After each interrupted test, specimens are unloaded and free edges are investigated with an optical microscope to capture damage mode, then the same specimen is tested to the next interruption levels in different tests until the ultimate failure is achieved.

This test procedure is actually a "cyclic loading". Besides, simultaneous AE registration and optical observations at the end of each cycle provides "partially in-situ damage detection". Experimental setup can be seen in Figure 3. White dots on the specimens are used to define the gauge lengths for the axial and transverse strain measurements by the video extensometer.

Figure 3. Tension test setup

\subsection{Acoustic emission registration}

A two-channel MISTRAS AE-Node system is used during the tension tests of TCT $[0]_{5}$ specimens. PAC AEWin software is used for data acquisition [35]. Two resonant type PK15I sensors, having $20.6 \mathrm{~mm}$ diameter are used to emit the signals of damage modes during tension tests [36]. Their operating frequency range is between $100-450 \mathrm{kHz}$ and the resonant frequency is $150 \mathrm{kHz}$. This frequency range is suitable for matrix dominated damage modes. The contact surfaces of AE sensors are covered with ultrasound coupling gel and they are placed on test specimens with spring clamps as shown in Figure 3. Noise or redundant 
signals during $\mathrm{AE}$ monitoring is considered as one of the predominant problems. In order to filter the background noise coming from the servo-hydraulic test machine, amplitude threshold level during the tests is adjusted to $55 \mathrm{~dB}$. Since it is not easy to eliminate all noise signals, a post-processing filter is applied additionally. In this filtering, only the signals that are consecutively recorded by both sensors with an arrival time difference of less than and equal to $1 \mathrm{~ms}$ are kept as correspondence of a damage mode while the other signals are filtered out.

As shown in the following sections, it is observed that damage development in each test is detected when the maximum stress level of the previous interruption level is exceeded. The AE technique enables to record a small amount of damage during short intervals between maximum stresses of the previous and the current tests, which are proved by post-optical observations after each test. Different damage modes are observed between maximum stress levels of each test. Single AE parameters are used to analyse and correlate the AE characteristics with observed damage modes at the end of each interrupted test.

However, the use of single AE parameters is not sufficient for reliable correlations between the damage modes and AE events. Hence, the k-means++ clustering algorithm is used to evaluate and cluster AE events, which offers a reliable classification of $\mathrm{AE}$ events and correlations with the damage modes. The effectiveness of the k-means++ clustering algorithm in terms of grouping the similar AE events and providing reliable correlations between the clusters and damage modes are proved in various studies $[23,26,28,29]$. This algorithm is applied to UD laminates for the first time in this study. Detailed information about this clustering algorithm can be found in previous studies [23,26,28,29] and a brief summary is given here; Laplacian score and correlation coefficients are used to choose relevant and selective AE parameters first. Then multidimensional AE data are transformed to lower dimensions with Principal Component Analysis (PCA) and the similar AE events are grouped into clusters with the k-means++ algorithm according to the optimal cluster numbers obtained with respect to the Silhouette Coefficient and DaviesBouldin index. Low Davies-Bouldin index with high Silhouette coefficient represent well-separated and dense clusters and the optimal cluster number is determined with respect to this combination. 


\section{Finite element model}

For numerical analysis of progressive failure in composite laminates, capabilities of the ABAQUS/Standard FE software package [37] is explored. The FE model is shown in Figure 4. Note that the gripping region of the specimen is not considered in this model. A 3D deformable solid extruded part is created with a thickness of $0.924 \mathrm{~mm}$ including five $0.184 \mathrm{~mm}$ thick composite plies and $0.001 \mathrm{~mm}$ thick cohesive layers in between plies and the slit. The composite plies are defined by assigning composite layup with continuum shell elements using the material properties given in Table 1. The cohesive properties, shown in Table 2, have been applied to the cohesive layers in section assignment using traction-separation response.

Figure 4. Partitions for the TCT specimen FE model

Table 2. Interlaminar strength, fracture energy and stiffness parameters for cohesive elements

An implicit step (static general) with the time period of 1 second is generated for the analysis. In order to include nonlinear effects of large deformations and displacements, non-linear geometry option (NLGEOM) is activated in the step module. An automatic time incrementation with an initial increment size of 0.01 is applied, where the size of subsequent increments will be adjusted based on how quickly the analysis converges. Choosing a fixed time incrementation is not recommended due to the possibility of causing convergence problems. The whole part is meshed with hexahedral elements using swept meshing technique. Due to the distinctive directional behaviour of continuum shell and cohesive elements, a through-thethickness mesh stack direction should be assigned to the part in the mesh module. Continuum shell elements (SC8R), having the geometry of continuum solids but kinematic and constitutive behavior analogous to conventional shell elements, with linear geometric order and enhanced hourglass control, are selected as element types for modeling composite plies. Cohesive elements (COH3D8), defined for the interfacial debonding based on a traction-separation description of the interface, are selected for the cohesive layers. 
The element deletion option is activated in assigning the element types. A nodal displacement with a tabular amplitude over the step time is applied to the tip node, which is connected to all nodes on the right edge surface of the specimen using an equation type constraint. The mesh structure and assigned boundary conditions are shown in Figure 5.

Figure 5. Mesh structure and assigned boundary conditions

\section{Results and discussion}

\subsection{Mechanical test results and comparison with finite element analysis predictions}

It is not possible to determine the damage progression without using the $\mathrm{AE}$ technique, since the stressstrain response of the CFRP specimen are upwardly concave, which means that the specimens stiffen as the load increases. This is obviously seen during the tension test of non-slit $[0]_{5}$ specimen in Figure 6. It is also present in the TCT test. Even though it is known that damage occurs in the resin-rich slit regions of these specimens during testing, the elastic modulus continues to increase during the test as seen in Figure 7.

The tension stress-strain response of a TCT $[0]_{5}$ specimen is compared with the FE model in Figure 8 . There is a very good consistency between the stress-strain responses of the TCT test and the FE model. The great agreement between the measured and predicted mechanical properties is presented in Table 3 . It should be noted that the elastic modulus for the TCT specimen is actually the "apparent modulus" or stiffness, which reflects the increase in the compliance due to the discontinuity of the fibres in the mid-ply. Two noninterrupted tests are applied with online AE registration to each specimen type to determine the interruption stress levels. Then, three specimens are tested with eight interruptions for each specimen. Results of eight tests are taken into consideration for elastic modulus and Poisson's ratio values, whereas five test results are considered for strength values for each specimen type (two from non-interrupted tests and three from interrupted tests). The agreements between the tension test results and the FE model proves that the FE 
model is valid for progressive damage analysis and can be compared to the observations from the actual tests.

Figure 6. Stress-strain curve of non-slit $[0]_{5}$ specimen

Figure 7. TCT stress-strain curve of TCT $[0]_{5}$ specimen.

Figure 8. Comparison between a tension test and FE model for TCT [0]5-specimen.

Table 3. Mechanical Test Results for 5-plies UD specimens

\subsection{Damage mode identification}

Damage progression during the TCT tests of $[0]_{5}$ specimens is presented in this section. Maximum stress levels for the interrupted tests are determined from the plot of cumulative number of AE events registered during uninterrupted tension test. Figure 9 shows the stress-strain curve of an uninterrupted test together with the cumulative number of registered $\mathrm{AE}$ events and demonstrates how the interruption levels are determined. The maximum stress levels of the interrupted tests are chosen to be the points just after the cumulative number of registered AE events exhibits a sudden increase in Figure 9.

Figure 9. Uninterrupted stress-strain curve and number of registered AE events for TCT specimen.

The AE characteristics of the interrupted tests can be seen in Figure 10 (each colour represents a different interruption level as labelled below the graphs). AE results confirm that amplitude in Figure 10.a and duration in Figure 10.b show selective characteristics rather than peak frequency (P-FRQ) in Figure 10.c. First registered events, between 750 - 950 MPa stress levels, have high amplitude and high duration characteristics, whereas the registered AE events at high strain levels have low values when the specimen is loaded to between $1400-1600 \mathrm{MPa}$, and finally, at the end of the last interrupted test, high amplitude and high duration events are registered during final failure of the specimen. Peak frequency is assumed to 
be one of the most characteristic parameters for damage mode classification in literature. However, it is not a distinctive parameter for slit-specimens in Figure 10.c. Interestingly, it is seen that a very rarely used parameter, average frequency (A-FRQ), provides a distinctive classification for registered AE parameters. Average frequency is calculated by dividing the total number of threshold crossing peaks to the total duration of an event. First registered AE events have low average frequency values, between 0-200 kHz, then during the last interrupted tests, the registered AE events are seen to have values between $0-400 \mathrm{kHz}$. Finally, AE events with very high average frequency values, at around $1000 \mathrm{kHz}$ are registered at high stress-strain levels between 1500 - $1650 \mathrm{MPa}$ in Figure 10.d. It should be mentioned that each colour in Figure 10 represents the $\mathrm{AE}$ events registered during different interrupted tests (named with respect to the maximum stress level of the interrupted test) but not different damage modes.

Figure 10. Interrupted tests of a slit-specimen with AE results

\subsubsection{Correlation of damage modes with single acoustic emission parameters}

A correlation between the damage modes, AE characteristics and stress-strain levels can be obtained by comparing the AE events in Figure 10 and the edge micrographs in Figure 11 which shows the micrographs of the damage modes at the end of interrupted tests. Maximum stress levels of each test are labelled on the left side of micrographs in Figure 11. It should be noted that both edges of the specimens are observed with an optical microscope and they are labelled as "front" and "back" in Figure 11.

The grey coloured AE events that are registered between 750-950 MPa correspond to matrix crack and fibre/matrix debonding at fibre/resin pocket intersections. This can be noticed by comparing the circled regions in "INITIAL" and "1100" rows in Figure 11. Amplitude range of recorded signals is between 60-80 $\mathrm{dB}$, where the duration of signals is mostly between $60-200 \mu \mathrm{s}$. There is no change in damage when the specimen is loaded until $1300 \mathrm{MPa}$ in Figure 11 and few AE events, can be seen with red colour, are registered during the interrupted test ended at $1300 \mathrm{MPa}$ in Figure 10. During the interrupted test until 1500 
$\mathrm{MPa}$, it is seen that $\mathrm{AE}$ events with low amplitude and low duration values begin to be recorded. Green colour events in Figure 10, are mostly due to delamination initiations as highlighted in Figure 11 for 1500 $\mathrm{MPa}$. At the end of the next interrupted test with a maximum stress of $1600 \mathrm{MPa}$, delaminations at the corners of resin pockets propagate and become more visible in micrographs as pointed out in Figure 11. AE characteristics of these signals have a low amplitude with low duration characteristics as well. Final failure occurs at $1650 \mathrm{MPa}$ in the last test, where many $\mathrm{AE}$ signals are recorded with low amplitude and duration characteristics.

An interesting observation during the tests is that delaminations cause discontinuities between the plies and the travel time of the AE events of the damage modes increases. Hence, the arrival time difference of AE events between two sensors increases to $10 \mathrm{~ms}$ from $1 \mathrm{~ms}$ during the last test, due to the discontinuities through the length of the specimens because of the large delaminations between the plies. AE events recorded after this change are shown with pink colour in Figure 10. These AE events mostly have a low amplitude, low duration and high average frequency values which are believed to correspond to individual fibre breaks. Finally, AE events shown with pink colour in Figure 10, having high amplitude and duration levels, belong to final failure of the specimen with separation of large numbers of fibres from the matrix. Until now, all interpretations for correlations between the damage modes and AE parameters give a general trend but they are not sufficiently robust.

\subsubsection{Correlation of damage modes with the k-means++ clusters}

In order to distinguish the $\mathrm{AE}$ events and make reliable correlations with the damage modes, the k-means++ clustering algorithm is used. Optimal cluster number is found to be three with the k-means++ clustering algorithm. Distribution of three clusters throughout the tension test with respect to three different AE parameters are plotted with the stress-strain curve in Figure 12. The first cluster (CL1) has a broad range of amplitude and duration, and low average frequency characteristics. CL1 begins to be registered after 800 $\mathrm{MPa}$ as shown in Figure 12.a. Its accumulation is highly consistent with matrix cracking at the fibre/matrix interface in Figure 11. Thus, CL1 represents matrix cracking at the fibre/matrix interface of the resin 
pockets. Delamination onsets are observed when the specimen is loaded to $1500 \mathrm{MPa}$ in Figure 11 and the accumulation of CL2 is highly consistent with their propagation that begins to be registered after $1430 \mathrm{MPa}$ as seen in Figure 12.a. They have mid-duration and mid-average frequency characteristics. Then, the registration of a large number of CL3 events starts after $1500 \mathrm{MPa}$ as shown in Figure 12.c. They have very distinctive high average frequency (A-FRQ) characteristics. Although only the propagation of matrix cracks and delaminations are observed with optical micrographs, this distinctive, high average frequency AE characteristic should represent a different damage mode. It is highly possible that CL3 events are registered due to fibre breaks. Another assertion to justify this interpretation is their stress level, which is very close to the ultimate strength level of the specimen. Finally, high duration and low average frequency CL1 events are registered at the end of the test. They are the gross failure of the specimen in the form of large separation. Since they contain the separation of a large number of fibres from the matrix, the sound of this gross failure is audible which means that they have high amplitude and even high duration with low average frequency characteristics.

Figure 11. Damage progression in slit-specimen

Figure 12. Accumulation of AE clusters

The wave speed in the $[0]_{5}$ specimen is measured as $5500-5700 \mathrm{~mm} / \mathrm{ms}$. The location of damage is calculated within PAC AEwin software [35]. Figure 13 presents a very good correlation between the locations of AE events, propagation of damage modes and final failure mode of the specimen. It should be noted that the number of AE events in Figure 13 is less than their number in Figure 12. This is due to the fact that only one AE event of a damage is plotted in Figure 13.a, which is the event detected with location detecting AE sensor and is located at the bottom of the gage length shown in Figure 13.b.

The distance between the location detecting AE sensor to the resin pocket in the specimen is $27 \mathrm{~mm}$. Figure 13.a. shows that the distance of CL1 events to the location detecting AE sensor is around $25 \mathrm{~mm}$. Even 
though there is a slight discrepancy between the real location of the damage and the AE location detection, this demonstrates a very good agreement between CL1 and the matrix cracks at the fibre/matrix interface in the resin pocket. Delamination propagation can be traced easily from the accumulation of CL2 events through the length of the specimen in Figure 13.a. When compared with final failure view of the specimen, delamination propagations to further regions on the specimen length can be seen in Figure 13.b, which is highly consistent with the accumulation of CL2 events through the end of the test in Figure 13.a. It is seen that the CL1 events at the end of the test are registered around $10-15 \mathrm{~mm}$ distance to the location detecting AE sensor in Figure 13.a. This proves that these last CL1 events, having high amplitude and low average frequency characteristics, represent the splitting of the specimen including fibre breaks with gross failure of the matrix at the end of the test. Finally, CL3 events are believed to represent individual fibre breaks with high average frequency characteristics. It is not really easy to make strong correlations between them as previous damage modes but most of the CL3 events are seen to be recorded around $10 \mathrm{~mm}$ distance to location detecting AE sensor. It is consistent with fibre breaks, seen on the specimen in Figure 13.b and this justifies the correlation between high average frequency CL3 events with fibre breaks.

Figure 13. a) Location distribution of clusters throughout test and b) comparison with final failure. (Note that the image is resized for its length to match the AE Source Location axis.)

\subsection{Finite element based progressive damage analysis}

The consistency between the stress-strain diagrams of an uninterrupted tension test and the FE model is already given in Figure 8. In order to compare the experimentally observed damage modes with FE predictions, damage progressions at around the slit; matrix cracks at fibre/matrix interface of the resin pocket and delaminations, are demonstrated with their stress levels in Figure 14 and Figure 15. In these figures, stiffness degradation (SDEG) value for the cohesive elements reaches to unity at delamination 
onset. The element completely loses its capability to carry loads and forms a debonded area between adjacent plies.

Damage onset at the fibre/matrix interface of the resin pockets occurs at $749 \mathrm{MPa}$ stress level, at the expected locations on both sides of the slit as seen in Figure 14. As the applied strain increases, these regions extend and the upper and lower corner intersections between the slit and composite plies start to delaminate at $1449 \mathrm{MPa}$ as represented in Figure 15. Finally, matrix and fibre damage, based on Hashin's failure criterion for initiation and damage evolution in terms of fracture energy with linear softening, are shown in Figure 16. The intralaminar matrix damage within the continues plies initiates and then propagates at four corners of the slit in two adjacent composite plies as seen in Figure 16.a. The fibre damage initiates at the second and forth composite plies and extends to all five plies throughout the test as seen in Figure 16.b and causes the ultimate failure of the specimen at the stress level of $1578 \mathrm{MPa}$. The experimentally determined and numerically predicted stress levels for different damage modes are compared in Table 4. It is seen that the predictions of the FE model are in a very good agreement with the progression of damage modes and accumulation of their corresponding AE clusters as presented in Figure 11 and Figure 12.

This demonstrates that an FEA based progressive damage analysis, using experimentally measured material properties and proper methodology provides predictions of the damage modes of a composite laminate very closely. Furthermore, together with the AE localization technique, this analysis helps validation of the correlations between the AE clusters and damage modes.

Figure 14. Initiation of matrix cracking at resin pocket/fibre intersection at a stress level of $749 \mathrm{MPa}$ ( $\mathrm{SDEG}=1$ for side cohesive elements).

Figure 15. Delamination at the stress level of $1449 \mathrm{MPa}(\mathrm{SDEG}=1)$ with extended side cohesive elements and initiation for upper and lower cohesive elements 
Figure 16. a) Hashin's matrix and b) Hashin's fibre tensile failure pattern at the ultimate failure stress (1578 MPa)

Table 4. Comparison of damage modes stress levels in experiments and FE model

\section{CONCLUSION}

In this study, AE characteristics of damage modes in TCT [0] specimens are clearly identified with simultaneous AE registration and supportive optical microscopy technique. The introduced slit in the midply of TCT specimens enables to stimulate damage in an anticipated order of matrix cracking - fibre/matrix debonding - delamination and fibre breaks. In order to identify the induced damage modes and correlate them with registered AE events, the specimen edges are investigated under an optical microscope at certain stress levels where the test is interrupted. This method actually is cyclic loading with partially in-situ damage detection. The k-means++ clustering algorithm is used to group similar AE events to provide reliable correlations between the registered $\mathrm{AE}$ events and the observed damage modes. First observed damage mode is matrix cracking with fibre/matrix debonding at the boundaries of the plies and resin pocket and have broad amplitude and duration with low average frequency AE characteristics. This is followed by delaminations, initiating from the corners of the resin pockets which are registered with lower amplitude and duration signals. It is seen that discontinuities between plies, caused by delaminations, change the wave propagation path within the material and would increase the travel time of emitted waves. Afterward, individual fibre breaks are detected with AE signals having lowest amplitude and duration but the highest average frequency values. Finally, the specimens are separated due to a large number of fibre breaks registered with the highest amplitude and duration values. These correlations are supported with AE localization technique that provides a very good consistency between the accumulation of AE events and damage mode progression.

A progressive finite element analysis, which takes into account both intralaminar and interlaminar failure modes is utilized to predict damage progression and verify AE results. In this model, in-plane damage 
modes of the composite plies are modeled with Hashin's failure criterion and the delamination and the fibre/matrix debonding at the edges of the resin pockets are modeled using cohesive elements. The sequence of the damage modes, their onset stress levels and the ultimate strength prediction of the model is highly consistent with experimentally observed damage mode progression and the accumulation of their corresponding AE clusters, which builds confidence in virtual testing of composite materials and structures.

\section{Acknowledegments}

Authors acknowledge the support of the Boğaziçi University Research Fund and Istanbul Development Agency (ISTKA), under project codes 10020/15A06D3, and ISTKA/BIL/2012/58 respectively. Authors also acknowledge Professor S.V. Lomov from University of Leuven for the k-means++ clustering algorithm.

\section{REFERENCES}

[1] Takaku A, Shioya M. X-ray measurements and the structure of polyacrylonitrile- and pitch-based carbon fibres. J Mater Sci 1990;25:4873-9. doi:10.1007/BF01129955.

[2] Shioya M, Hayakawa E, Takaku a. Non-hookean stress-strain response and changes in crystallite orientation of carbon fibres. J Mater Sci 1996;31:4521-32. doi:10.1007/BF00366347.

[3] Djordjevic IM, Sekulic DR, Mitric MN, Stevanovic MM. Non-Hookean Elastic Behavior and Crystallite Orientation in Carbon Fibers. J Compos Mater 2010;44:1717-27. doi:10.1177/0021998309357087.

[4] Bogdanovich AE, Karahan M, Lomov S V, Verpoest I. Quasi-static tensile behavior and damage of carbon / epoxy composite reinforced with 3D non-crimp orthogonal woven fabric. Mech Mater 2013;62:14-31. doi:10.1016/j.mechmat.2013.03.005. 
[5] Barré S, Benzeggagh ML. On the use of acoustic emission to investigate damage mechanisms in glass-fibre-reinforced polypropylene. Compos Sci Technol 1994;52:369-76.

[6] de Groot PJ, Wijnen PAM, Janssen RBF. Real-time frequency determination of acoustic emission for different fracture mechanisms in carbon/epoxy composites. Compos Sci Technol 1995;55:40512. doi:10.1016/0266-3538(95)00121-2.

[7] Ceysson O, Salvia M, Vincent L. Damage mechanisms characterisation of carbon fibre/epoxy composite laminates by both electrical resistance measurements and acoustic emission analysis. Scr Mater 1996;34:1273-80. doi:10.1016/1359-6462(95)00638-9.

[8] Bohse J. Acoustic emission characteristics of micro-failure processes in polymer blends and composites. Compos Sci Technol 2000;60:1213-26. doi:10.1016/S0266-3538(00)00060-9.

[9] Huguet S, Godin N, Gaertner R, Salmon L, Villard D. Use of acoustic emission to identify damage modes in glass fibre reinforced polyester. Compos Sci Technol 2002;62:1433-44. doi:10.1016/S0266-3538(02)00087-8.

[10] Godin N, Huguet S, Gaertner R, Salmon L. Clustering of acoustic emission signals collected during tensile tests on unidirectional glass/polyester composite using supervised and unsupervised classifiers. NDT E Int 2004;37:253-64. doi:10.1016/j.ndteint.2003.09.010.

[11] Godin N, Huguet S, Gaertner R. Integration of the Kohonen's self-organising map and k-means algorithm for the segmentation of the AE data collected during tensile tests on cross-ply composites. NDT E Int 2005;38:299-309. doi:10.1016/j.ndteint.2004.09.006.

[12] Ramirez-Jimenez CR, Papadakis N, Reynolds N, Gan TH, Purnell P, Pharaoh M. Identification of failure modes in glass/polypropylene composites by means of the primary frequency content of the acoustic emission event. Compos Sci Technol 2004;64:1819-27. doi:10.1016/j.compscitech.2004.01.008. 
[13] Loutas TH, Kostopoulos V, Ramirez-Jimenez C, Pharaoh M. Damage evolution in center-holed glass/polyester composites under quasi-static loading using time/frequency analysis of acoustic emission monitored waveforms. Compos Sci Technol 2006;66:1366-75. doi:10.1016/j.compscitech.2005.09.011.

[14] Bourchak M, Farrow IR, Bond IP, Rowland CW, Menan F. Acoustic emission energy as a fatigue damage parameter for CFRP composites. Int J Fatigue 2007;29:457-70. doi:10.1016/j.ijfatigue.2006.05.009.

[15] Bussiba A, Kupiec M, Ifergane S. Damage evolution and fracture events sequence in various composites by acoustic emission technique. Compos Sci Technol 2008;68:1144-55. doi:10.1016/j.compscitech.2007.08.032.

[16] Gutkin R, Green CJ, Vangrattanachai S, Pinho ST, Robinson P, Curtis PT. On acoustic emission for failure investigation in CFRP: Pattern recognition and peak frequency analyses. Mech Syst Signal Process 2011;25:1393-407. doi:10.1016/j.ymssp.2010.11.014.

[17] Cuadra J, Vanniamparambil PA, Hazeli K, Bartoli I, Kontsos A. Damage quantification in polymer composites using a hybrid NDT approach. Compos Sci Technol 2013;83:11-21. doi:10.1016/j.compscitech.2013.04.013.

[18] Kempf M, Skrabala O, Altstädt V. Reprint of: Acoustic emission analysis for characterisation of damage mechanisms in fibre reinforced thermosetting polyurethane and epoxy. Compos Part B Eng 2014;65:117-23. doi:10.1016/j.compositesb.2014.05.003.

[19] Prieß T, Sause MG, Fischer D, Middendorf P. Detection of delamination onset in laser-cut carbon fiber transverse crack tension specimens using acoustic emission. J Compos Mater 2015;49:2639_ 47. doi:10.1177/0021998314552003.

[20] Baker C, Morscher GN, Pujar V V., Lemanski JR. Transverse cracking in carbon fiber reinforced 
polymer composites: Modal acoustic emission and peak frequency analysis. Compos Sci Technol 2015;116:26-32. doi:10.1016/j.compscitech.2015.05.005.

[21] Maillet E, Baker C, Morscher GN, Pujar V V., Lemanski JR. Feasibility and limitations of damage identification in composite materials using acoustic emission. Compos Part A Appl Sci Manuf 2015;75:77-83. doi:10.1016/j.compositesa.2015.05.003.

[22] Li L, Lomov S V., Yan X, Carvelli V. Cluster analysis of acoustic emission signals for 2D and 3D woven glass/epoxy composites. Compos Struct 2014;116:286-99. doi:10.1016/j.compstruct.2014.05.023.

[23] Li L, Lomov S V., Yan X. Correlation of acoustic emission with optically observed damage in a glass/epoxy woven laminate under tensile loading. Compos Struct 2015;123:45-53. doi:10.1016/j.compstruct.2014.12.029.

[24] Li L, Swolfs Y, Straumit I, Yan X, Lomov S V. Cluster analysis of acoustic emission signals for 2D and 3D woven carbon fiber/epoxy composites. J Compos Mater 2016;50:1921-35. doi:10.1177/0021998315597742.

[25] Fotouhi M, Suwarta P, Jalalvand M, Czel G, Wisnom MR. Detection of fibre fracture and ply fragmentation in thin-ply UD carbon/glass hybrid laminates using acoustic emission. Compos Part A Appl Sci Manuf 2016;86:66-76. doi:10.1016/j.compositesa.2016.04.003.

[26] Carvelli V, D’Ettorre A, Lomov S V. Acoustic emission and damage mode correlation in textile reinforced PPS composites. Compos Struct 2017;163:399-409. doi:https://doi.org/10.1016/j.compstruct.2016.12.012.

[27] Mohammadi R, Najafabadi MA, Saeedifar M, Yousefi J, Minak G. Correlation of acoustic emission with finite element predicted damages in open-hole tensile laminated composites. Compos Part B Eng 2017;108:427-35. doi:10.1016/j.compositesb.2016.09.101. 
[28] Oz FE, Ersoy N, Lomov S V. Do high frequency acoustic emission events always represent fibre failure in CFRP laminates? Compos Part A Appl Sci Manuf 2017;103:230-5. doi:10.1016/j.compositesa.2017.10.013.

[29] Oz FE, Ersoy N, Mehdikhani M, Lomov S V. Multi-Instrument In-Situ Damage Monitoring in Quasi-isotropic CFRP Laminates Under Tension. Compos Struct 2018;196:163-80. doi:10.1016/j.compstruct.2018.05.006.

[30] Wisnom MR. On the Increase in Fracture Energy with Thickness in Delamination of Unidirectional Glass Fibre-Epoxy with Cut Central Plies. J Reinf Plast Compos 1992;11:897-909. doi:10.1177/073168449201100802.

[31] Cui W, Wisnom MR, Jones M. An Experimental and Analytical Study of Delamination of Unidirectional Specimens with Cut Central Plies. J Reinf Plast Compos 1994;13:722-39. doi:10.1177/073168449401300804.

[32] Sause MGR, Gribov A, Unwin AR, Horn S. Pattern recognition approach to identify natural clusters of acoustic emission signals. Pattern Recognit Lett 2012;33:17-23. doi:10.1016/j.patrec.2011.09.018.

[33] Hexcel. HexPly ® 8552 - Product Data Sheet - EU Version 2016:1-6.

[34] ASTM. D3039/D3039M: Standard Test Method for Tensile Properties of Polymer Matrix Composite Materials. Annu B ASTM Stand 2014;14:1-13. doi:10.1520/D3039.

[35] MISTRAS. Application of USB AE Node to Fatigue and Tension / Compression Tests. MISTRAS USB AE Node 2013.

[36] MISTRAS. PK15I Sensor Product Data Sheet. MISTRAS Prod 2011.

[37] Abaqus 6.14. Documentation 2014. 


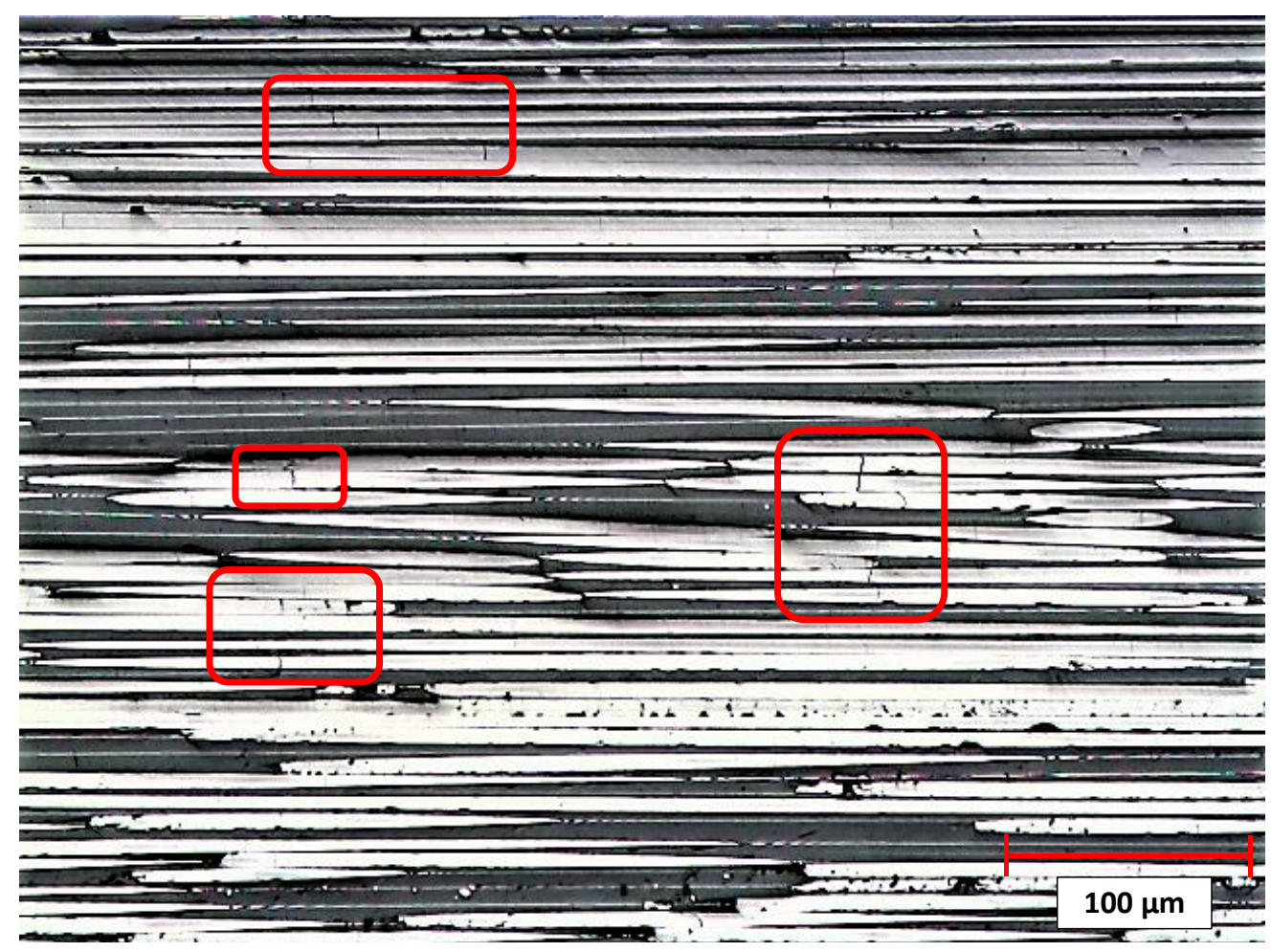

Figure 1 . Fibre breaks at $92 \%$ of the ultimate strength of $[0]_{5}$ specimen

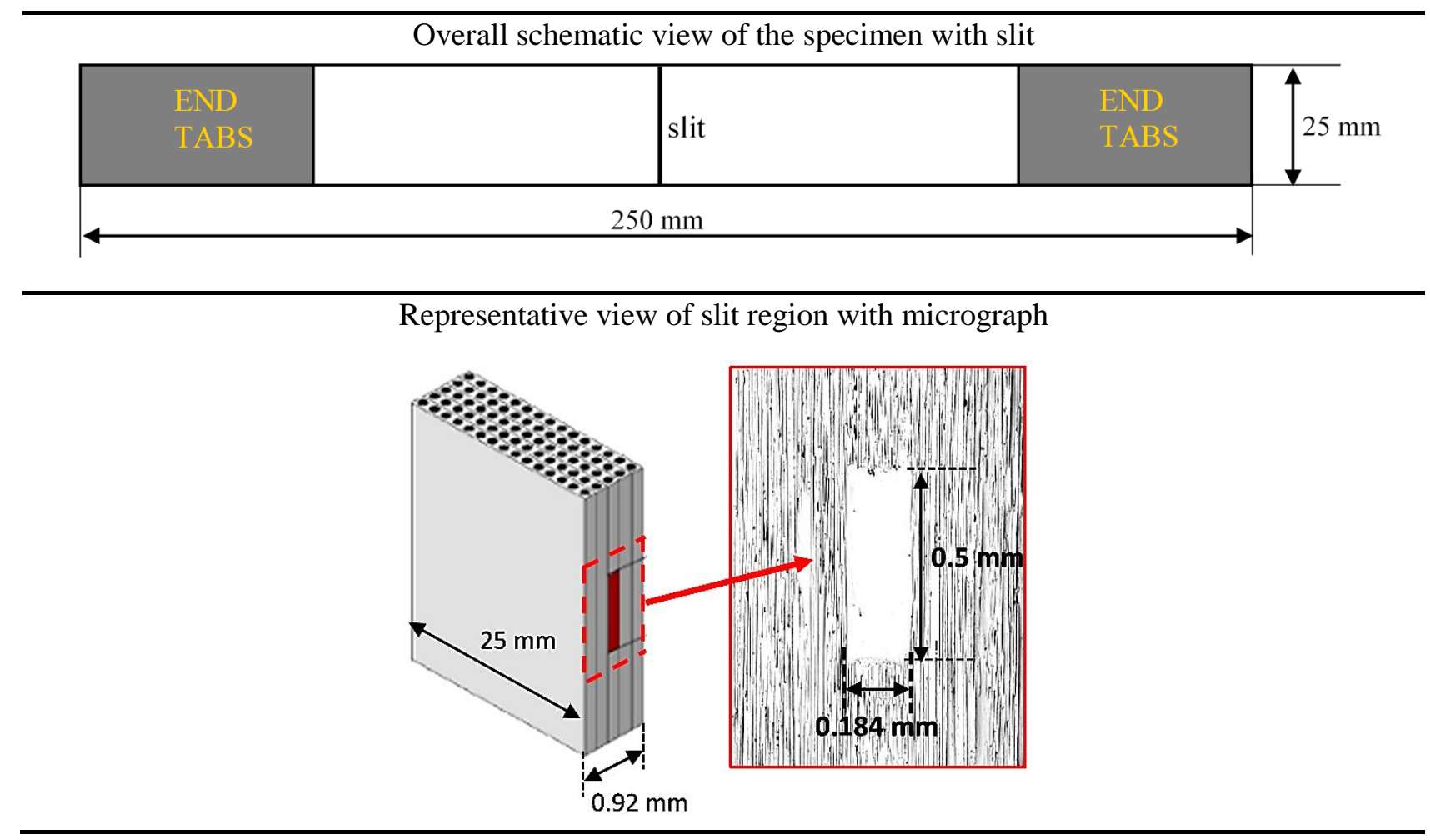

Figure 2. Schematic views of slit in TCT specimens 


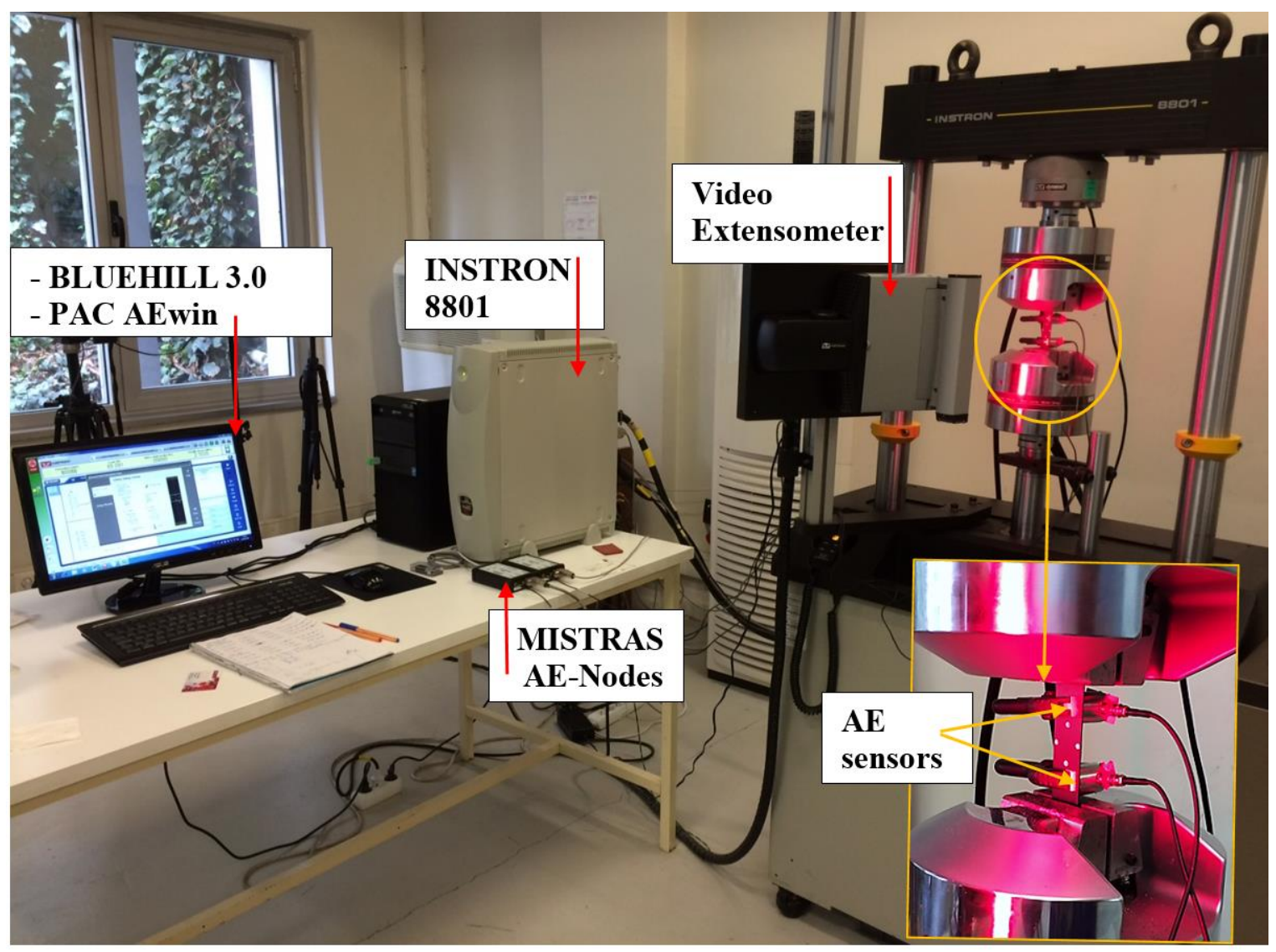

Figure 3. Tension test setup

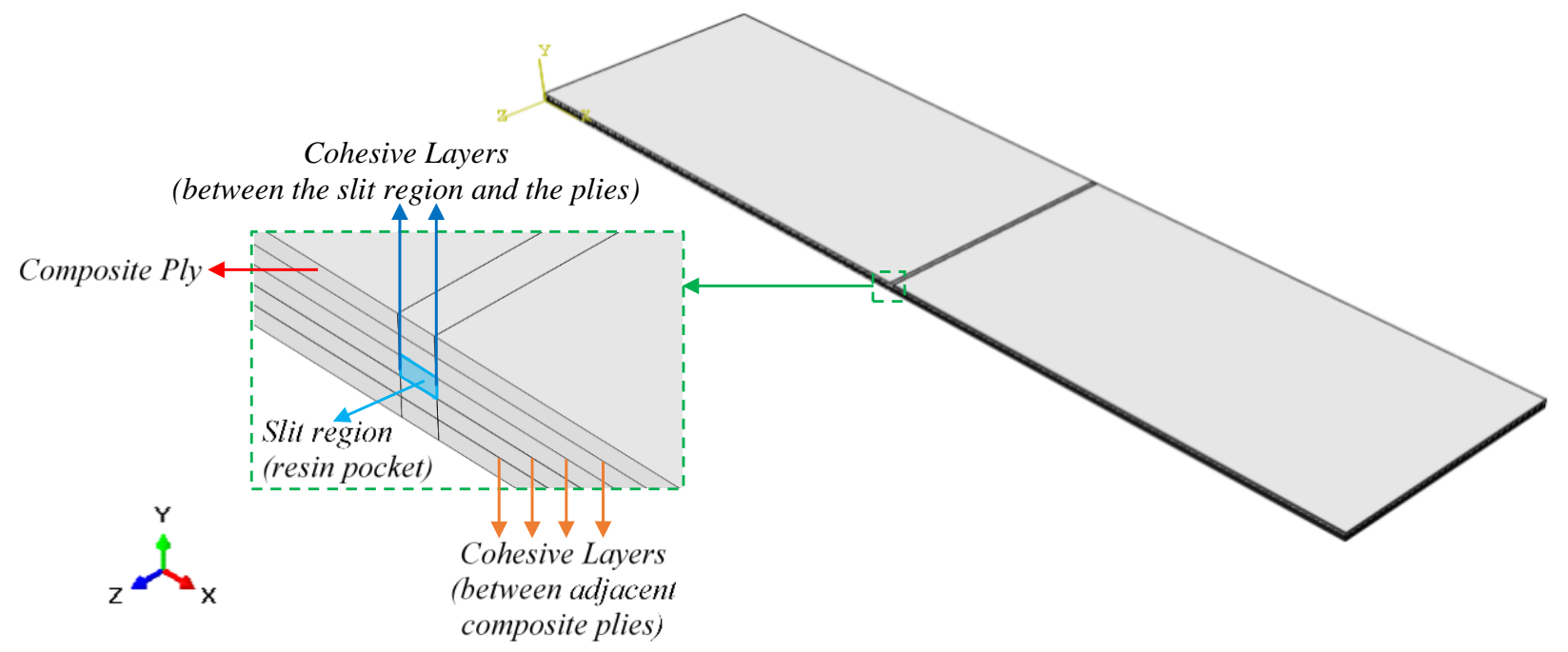

Figure 4. Partitions for the TCT specimen FE model 


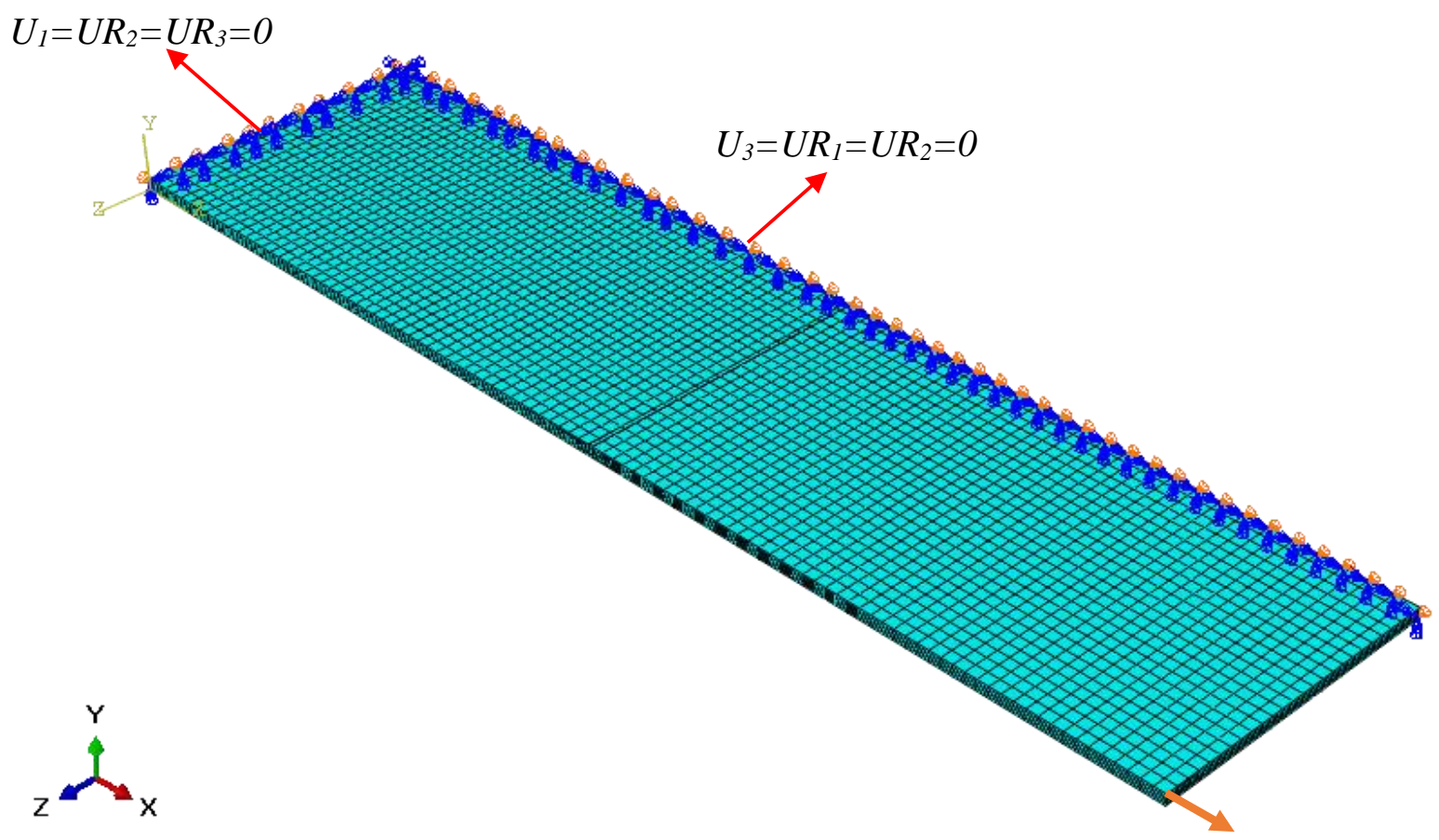

Nodal Displacement:

$\left(U_{1}=2 \mathrm{~mm}\right)$

Figure 5. Mesh structure and assigned boundary conditions

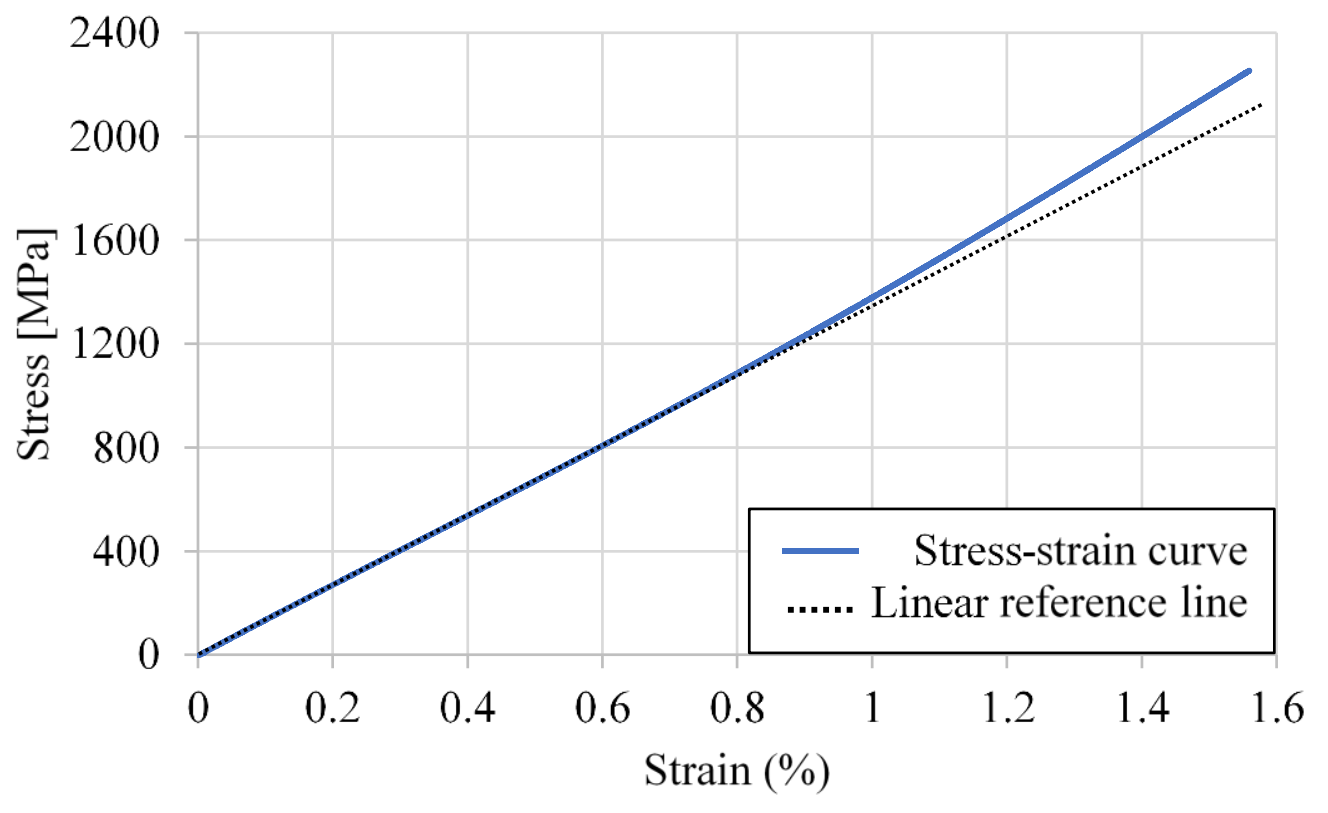

Figure 6. Stress-strain curve of non-slit $[0]_{5}$ specimen 


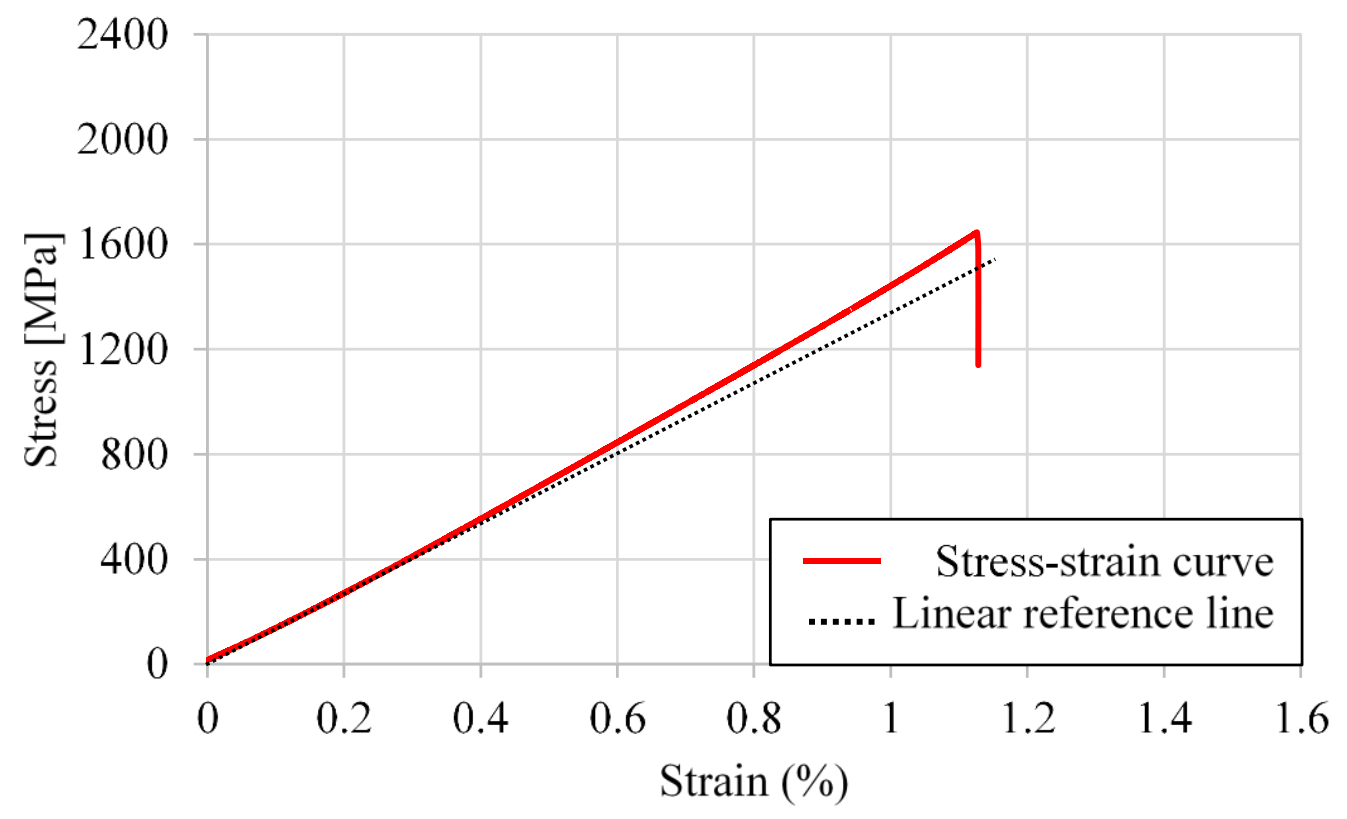

Figure 7. TCT stress-strain curve of TCT $[0]_{5}$ specimen.

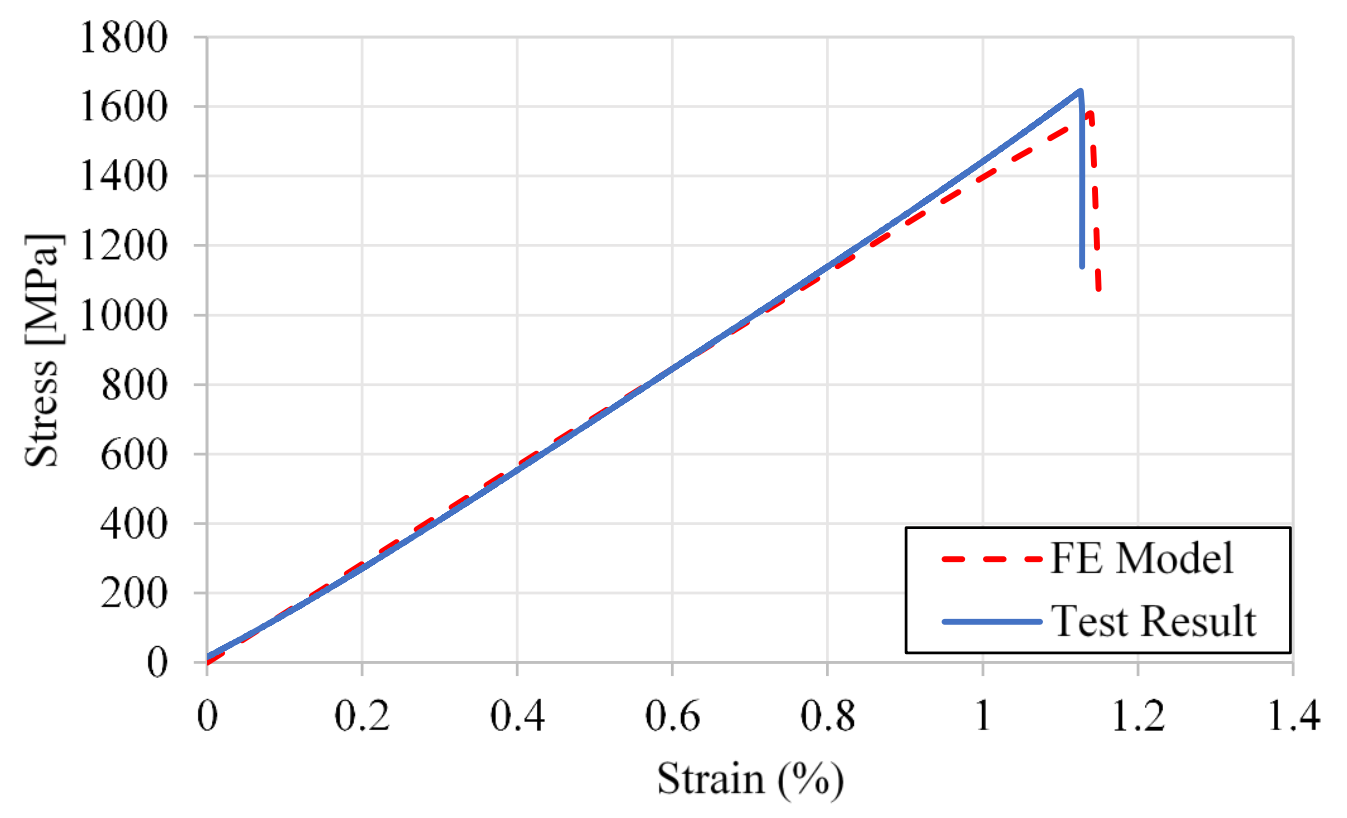

Figure 8. Comparison between a tension test and FE model for TCT $[0]_{5}$-specimen. 


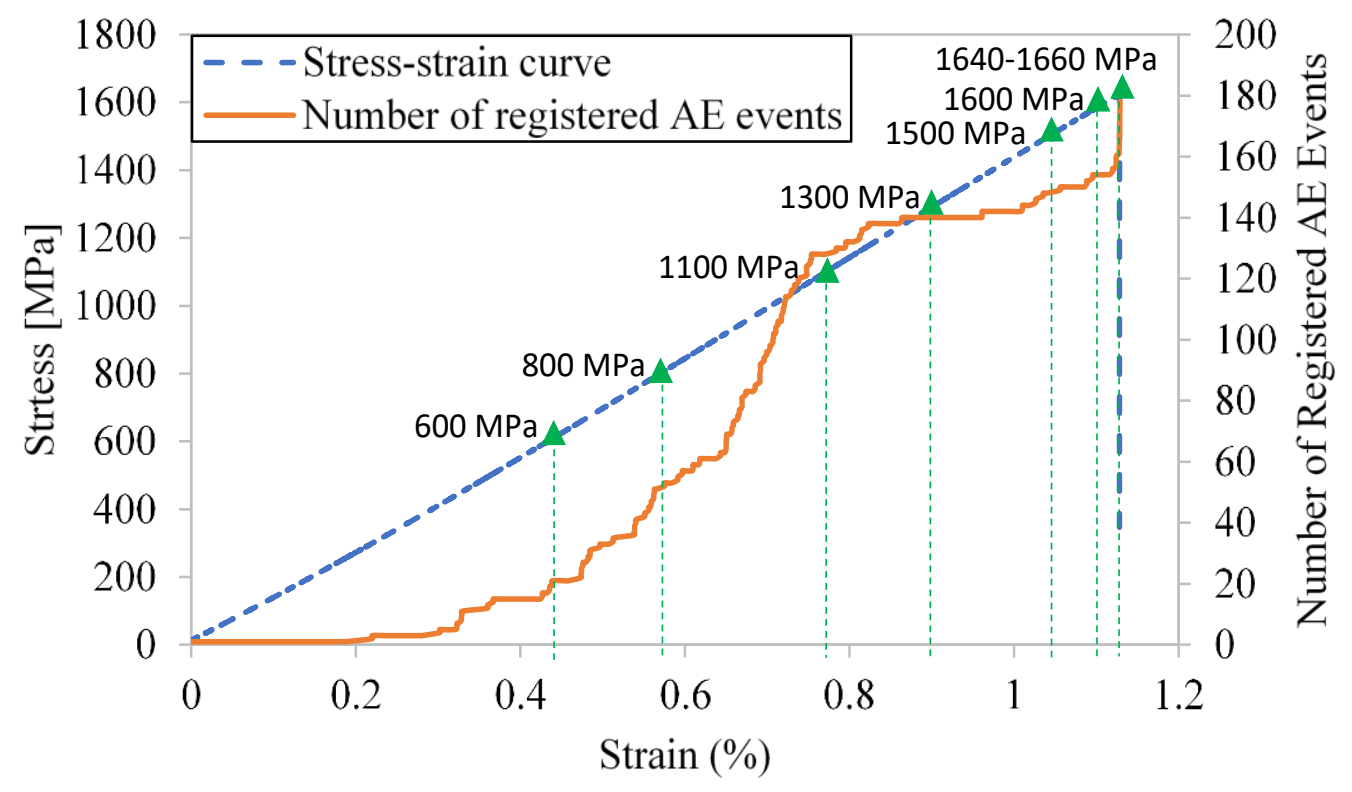

Figure 9. Uninterrupted stress-strain curve and number of registered AE events for TCT specimen.

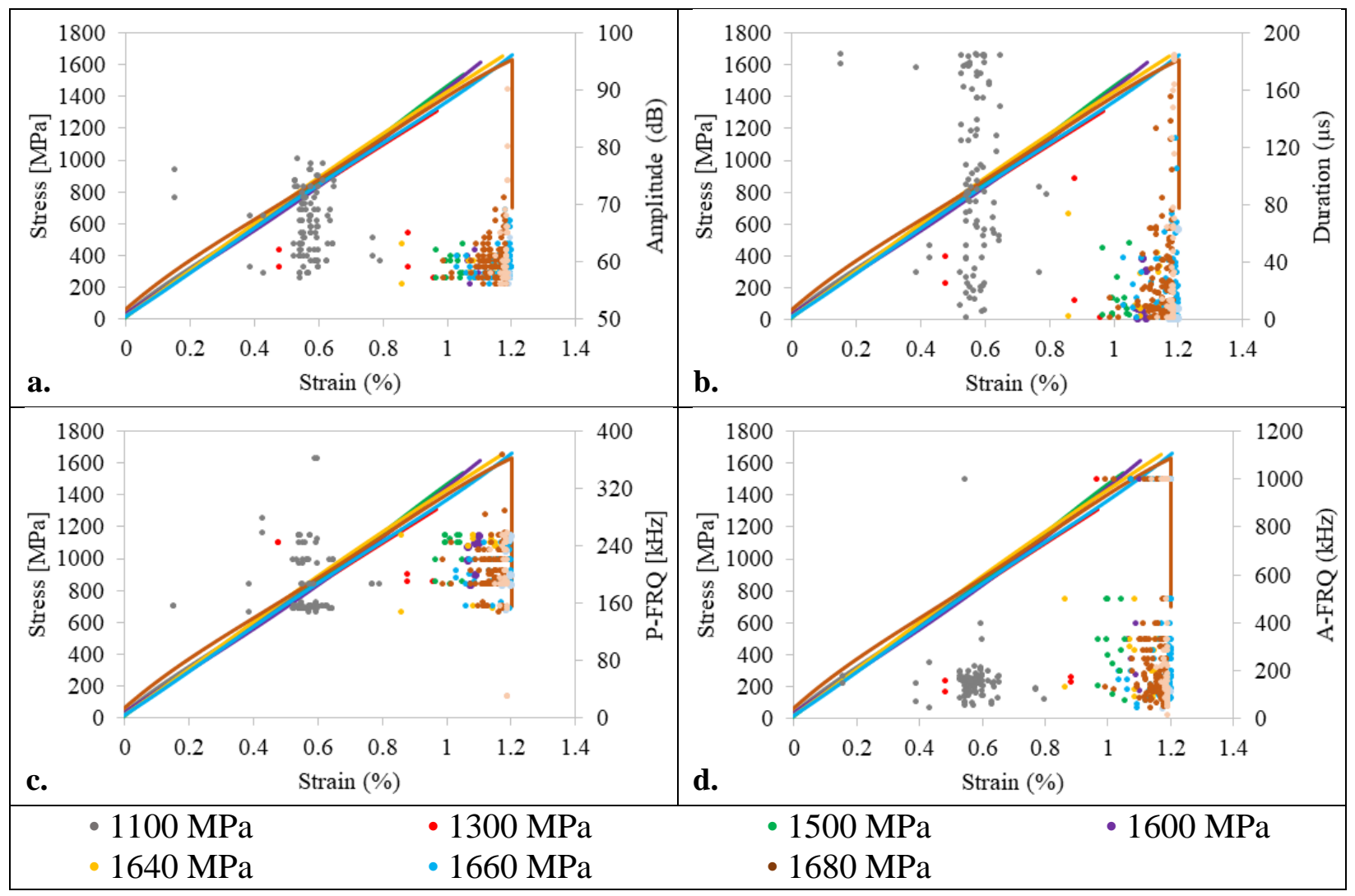

Figure 10. Interrupted tests of a slit-specimen with AE results 


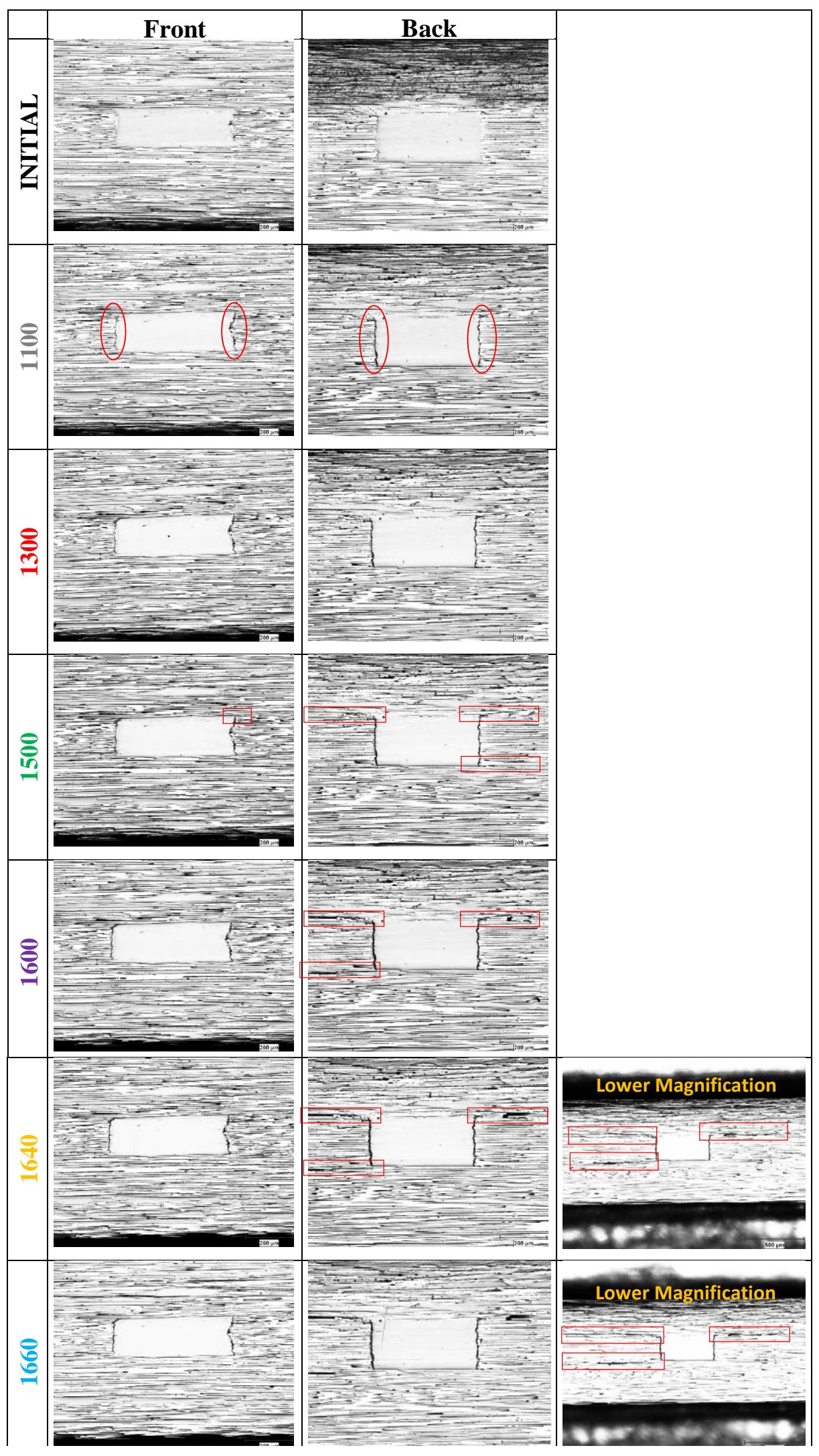

Figure 11. Damage progression in slit-specimen 

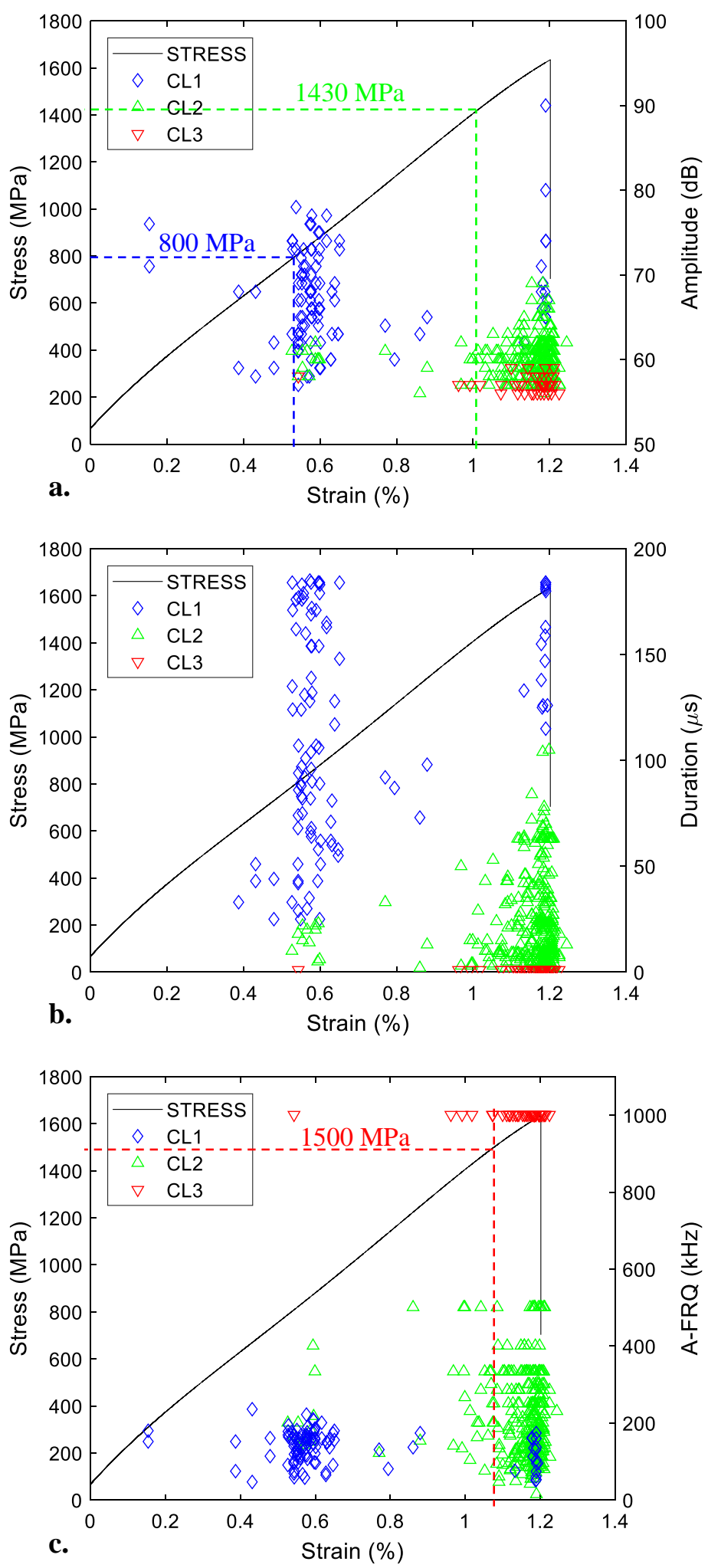

Figure 12. Accumulation of AE clusters 


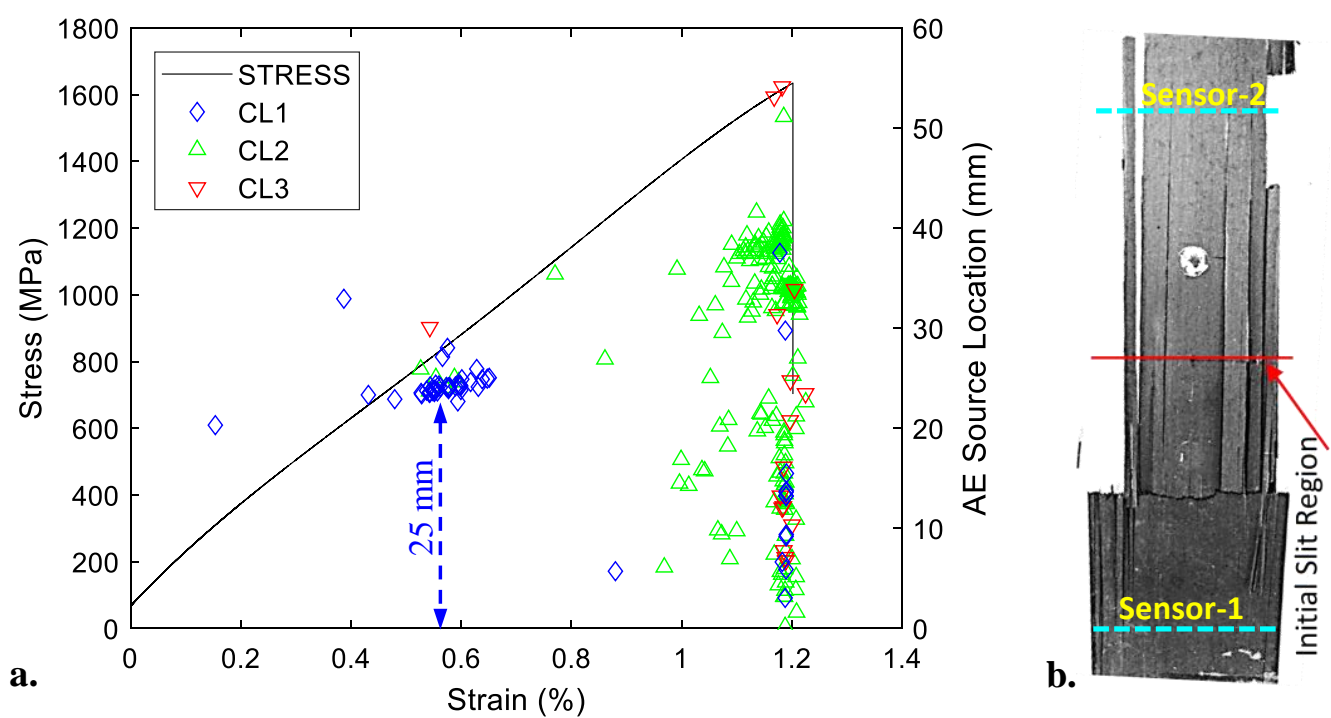

Figure 13. a) Location distribution of clusters throughout test and b) comparison with final failure. (Note that the image is resized for its length to match the AE Source Location axis.) 


\begin{tabular}{l|l|l|l|l|l|l}
\hline & & & & & & \\
\hline & & & & & & \\
\hline & & & & & & \\
\hline & & & & & & \\
\hline & & & & & & \\
\hline
\end{tabular}

Figure 14. Initiation of matrix cracking at resin pocket/fibre intersection at a stress level of $749 \mathrm{MPa}$ ( $\mathrm{SDEG}=1$ for side cohesive elements).

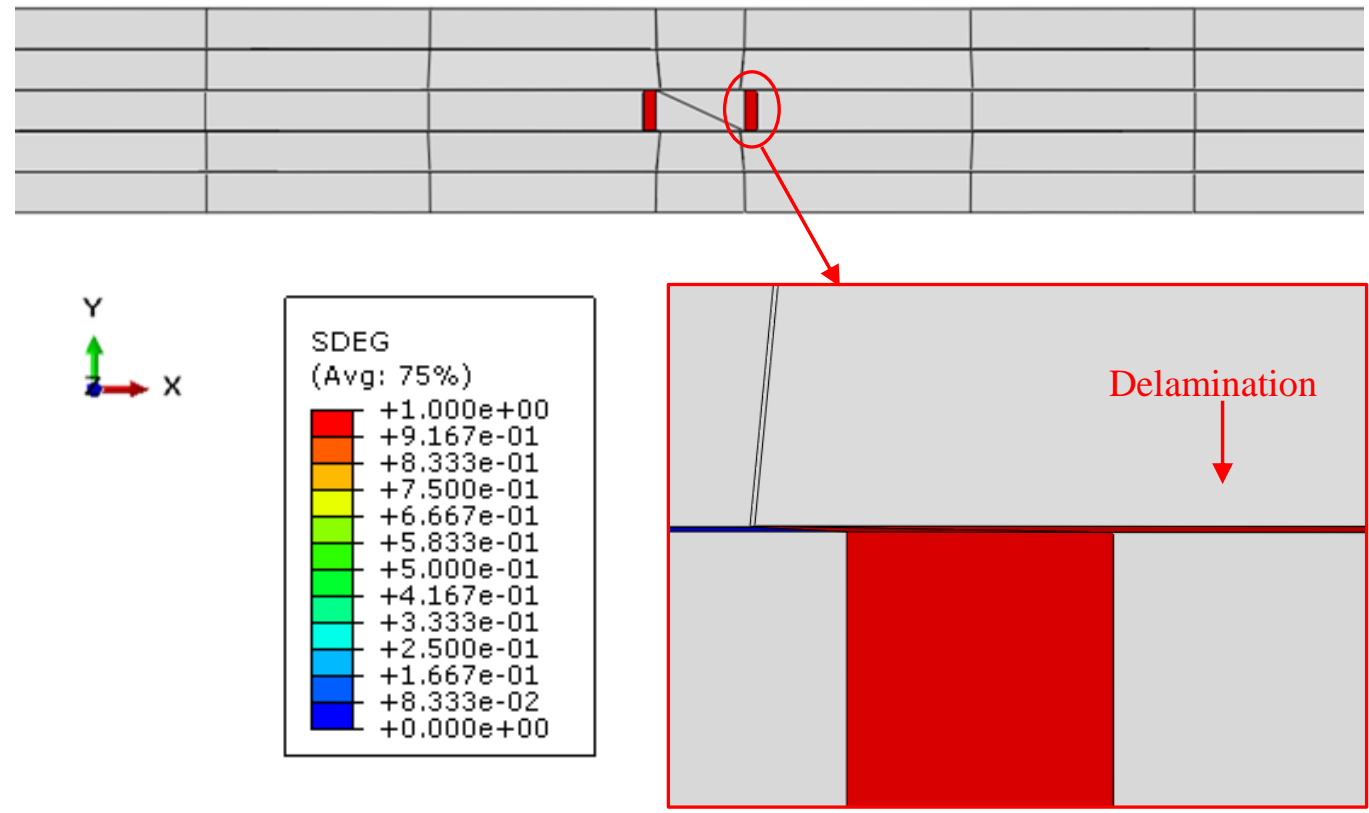

Figure 15. Delamination at the stress level of $1449 \mathrm{MPa}(\mathrm{SDEG}=1)$ with extended side cohesive elements and initiation for upper and lower cohesive elements 

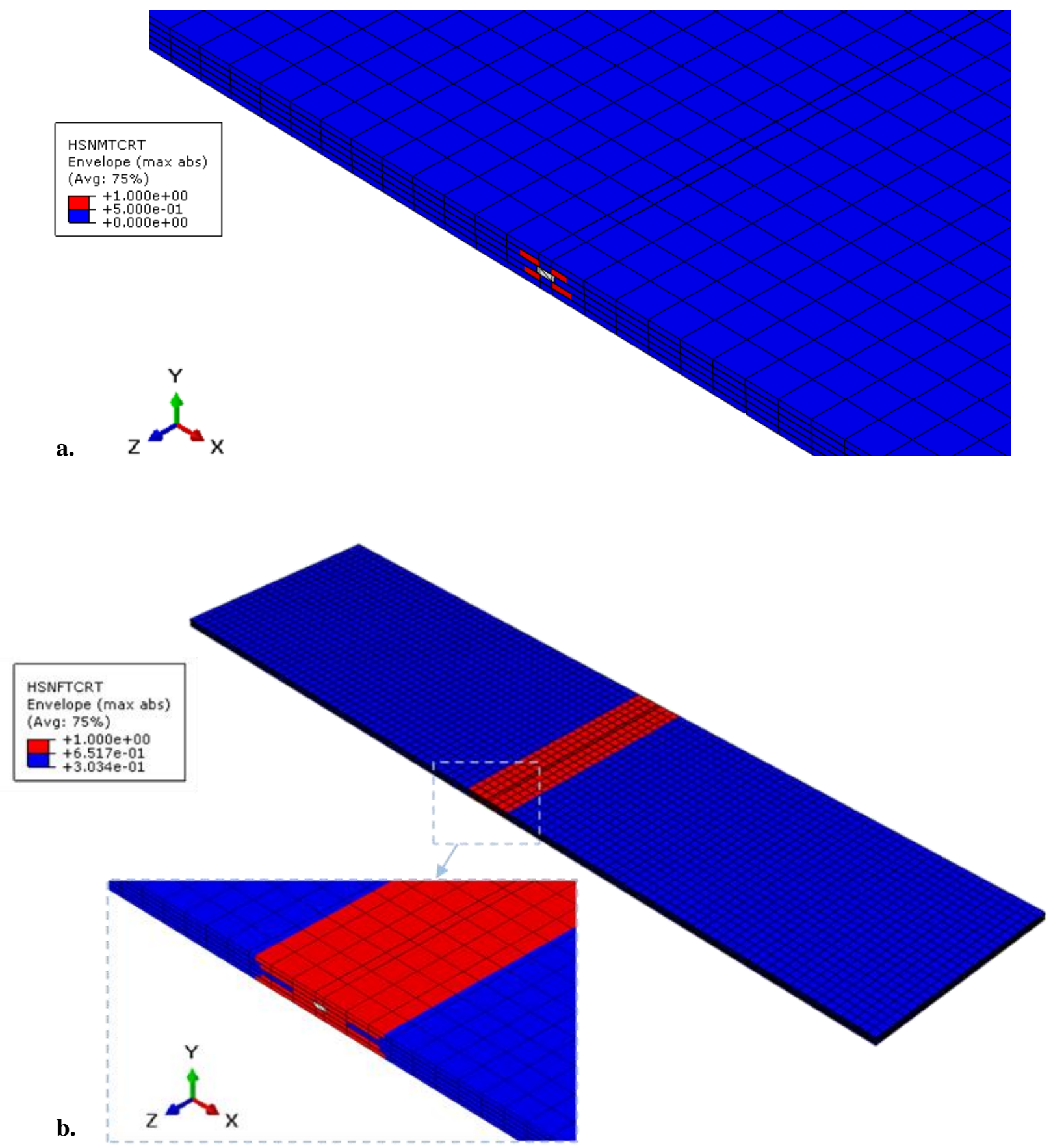

Figure 16. a) Hashin's matrix and b) Hashin's fibre tensile failure pattern at the ultimate failure stress $(1578 \mathrm{MPa})$ 
Table 1. Mechanical properties of AS4/8552

\begin{tabular}{|c|c|c|c|}
\hline & & Data Sheet [33] & FE Micromechanics \\
\hline $\mathrm{E}_{1}$ & $\mathrm{MPa}$ & 141000 & 142840 \\
\hline $\mathrm{E}_{2}=\mathrm{E}_{3}$ & $\mathrm{MPa}$ & 10000 & 10000 \\
\hline $\mathrm{G}_{12}=\mathrm{G}_{13}$ & $\mathrm{MPa}$ & - & 5571 \\
\hline $\mathrm{G}_{23}$ & $\mathrm{MPa}$ & - & 3278 \\
\hline$v_{12}=v_{13}$ & - & - & 0.263 \\
\hline$v_{23}$ & - & - & 0.525 \\
\hline$\sigma_{1}{ }^{\mathrm{T}}$ & $\mathrm{MPa}$ & 2207 & 2105 \\
\hline$\sigma_{1}{ }^{\mathrm{C}}$ & $\mathrm{MPa}$ & & 1531 \\
\hline$\sigma_{2}{ }^{\mathrm{T}}$ & $\mathrm{MPa}$ & 81 & 51 \\
\hline$\sigma_{2}{ }^{\mathrm{C}}$ & $\mathrm{MPa}$ & & 267 \\
\hline$\tau_{12}{ }^{\mathrm{S}}$ & $\mathrm{MPa}$ & & 114.5 \\
\hline
\end{tabular}

Table 2. Interlaminar strength, fracture energy and stiffness parameters for cohesive elements

\begin{tabular}{|c|c|c|c|}
\hline Property & Unit & Value & Reference \\
\hline$\sigma_{33 \mathrm{c}}$ & $\mathrm{MPa}$ & 81 & \\
\hline$\sigma_{13 \mathrm{c}}$ & $\mathrm{MPa}$ & 114 & \\
\hline $\mathrm{G}_{\mathrm{Ic}}$ & $\mathrm{kJ} / \mathrm{m}^{2}$ & 0.29 & {$[38]$} \\
\hline $\mathrm{G}_{\mathrm{IIc}}$ & $\mathrm{kJ} / \mathrm{m}^{2}$ & 1.15 & {$[39]$} \\
\hline $\mathrm{K}_{\mathrm{nn}}$ & $\mathrm{N} / \mathrm{mm}^{3}$ & $2.71 \times 10^{6}$ & \\
\hline $\mathrm{K}_{\mathrm{ss}}$ & $\mathrm{N} / \mathrm{mm}^{3}$ & $1.51 \times 10^{6}$ & \\
\hline \multicolumn{4}{|c|}{$[38]:$ with respect to ASTM D5528 [40] } \\
\hline \multicolumn{4}{|c|}{ [39]: with respect to ASTM D7905 [41] } \\
\hline
\end{tabular}


Table 3. Mechanical Test Results for 5-plies UD specimens

\begin{tabular}{|c|c|c|c|}
\hline & $\begin{array}{c}\mathrm{E}_{1}[\mathrm{MPa}] \\
(\text { c.v. } \%)\end{array}$ & $\begin{array}{c}v_{12} \\
(\text { c.v. } \%)\end{array}$ & $\begin{array}{c}\sigma_{1}{ }^{\mathrm{T}}[\mathrm{MPa}] \\
(\text { c.v. \%) }\end{array}$ \\
\hline No slit & $144000(1 \%)$ & $0.32(6 \%)$ & $2200(4 \%)$ \\
\hline FEM - No Slit & 142180 & 0.263 & 2172 \\
\hline Slit & $137000(2 \%)$ & $0.34(6 \%)$ & $1650(2 \%)$ \\
\hline FEM-Slit & 141000 & 0.263 & 1578 \\
\hline
\end{tabular}

Table 4. Comparison of damage modes stress levels in experiments and FE model

\begin{tabular}{|c|c|c|}
\hline & $\begin{array}{c}\text { Test Results } \\
\text { (c.v. \%) }\end{array}$ & FE Model \\
\hline Matrix Cracking & $787(2.4 \%)$ & 749 \\
\hline Delamination & $1441(1.4 \%)$ & 1449 \\
\hline Fibre Breaks & $1485(1.6 \%)$ & 1578 \\
\hline Ultimate Failure & $1652(1.95 \%)$ & 1578 \\
\hline
\end{tabular}

